\title{
Estudios Carcelarios: un capítulo teórico-metodológico de la historia de Criminalogía Moderna (Buenos Aires, 1899)
}

\author{
Estudios Carcelarios: A theoretical-methodological chapter of the history of \\ Criminalogía Moderna (Buenos Aires, 1899)
}

\author{
Federico Luis Abiuso \\ abiusofederico@yahoo.com.ar \\ Facultad de Ciencias Sociales, Argentina
}

Cita sugerida: Abiuso, F. L. (2020). Estudios Carcelarios: un capítulo teórico-metodológico de la historia de Criminalogía Moderna (Buenos Aires, 1899). Revista Latinoamericana de Metodología de las Ciencias Sociales, 10(2), e083. https://doi.org/10.24215/18537863e083

Recepción: 04 Diciembre 2019

Aprobación: 06 Agosto 2020

Publicación: 01 Diciembre 2020

\begin{abstract}
Resumen: Hacia el año 1899, Pietro Gori emprendió, junto a Juan Vucetich, un viaje de estudio a la Penitenciaría de Sierra Chica con el objetivo de estudiar al sistema carcelario de la Argentina y a la población allí recluida. Los resultados fueron publicados en Criminalogía Moderna (1898-1901), revista que Gori dirigió en su estadía en Buenos Aires, en una sección titulada Estudios Carcelarios. En el presente artículo propongo indagar en clave teórico-metodológica dicha sección; más concretamente, mi interés radica en describir de qué maneras fueron construidos los datos que refieren a las distintas características de la Penitenciaría y de los penados.
\end{abstract}

Palabras clave: Metodología de la investigación cualitativa, Datos visuales, Datos verbales, Criminología positivista.

\begin{abstract}
Towards the year 1899, Pietro Gori undertook, together with Juan Vucetich, a study trip to the Penitenciaría de Sierra Chica with the aim of studying the prison system of Argentina and the detained population there. The results were published in Criminalogía Moderna (1898-1901), a journal that Gori directed during his stay in Buenos Aires, in a section entitled Estudios Carcelarios. In this article, I propose to investigate this section in theoretical and methodological terms; more specifically, my interest lies in describing in what ways the data referring to the different characteristics of the Penitenciaría and the convicted were constructed.
\end{abstract}

Keywords: Qualitative research methodology, Visual data, Verbal data, Positivist Criminology.

\section{INTRODUCCIÓN}

Incursionar en el proceso de investigación social involucra que tomemos, en cada una de sus etapas, decisiones teórico-metodológicas de diversa índole y referidas a distintos aspectos. La noción de estrategia de investigación a la cual refieren Gabriela Gómez Rojas y Néstor Cohen (2003) condensa muchas de esas decisiones, presentadas a la manera de preguntas: ¿Qué es lo que se ha de investigar? ¿Respecto de quién se hará la indagación? ¿Cómo se obtendrá la información? ¿Cómo se realizará el análisis de los datos producidos? El presente artículo se centra en el tercero de ellos. Tomando a la vez como punto de partida y de inspiración la lectura que hizo Ricardo Salvatore (2013) del libro de Eusebio Gómez, La mala vida en Buenos Aires -escrito 
en 1908-, en términos de la existencia de un impulso empiricista; así como aquella que realizó José Daniel Cesano (2012) acerca de La delincuencia argentina ante algunas cifras y teorías (1905) de Cornelio Moyano Gacitúa, respecto al énfasis en la metodología utilizada por el autor para analizar de manera plurifactorial la cuestión criminal; el objetivo que me propongo en este artículo es realizar una indagación en clave teóricometodológica de los Estudios Carcelarios publicados por Pietro Gori en Criminalogía Moderna, revista que el abogado anarquista dirigió en su estadía en Buenos Aires, entre los años 1898 y 1901.

Más particularmente, Estudios Carcelariosconsistió en una sección editada entre abril y junio de 1899. Desagregada en cuatro artículos, el autor presentó allí resultados del viaje de estudio que emprendió, hacia el año 1899 y junto a Juan Vucetich, a la Penitenciaría de Sierra Chica, con el objetivo de estudiar al sistema carcelario de la Argentina y a la población que en aquel sitio se encerraba. Cada uno de los artículos que componen la sección estuvo orientado a una determinada temática: los aspectos externos e internos de la Penitenciaría, los distintos trabajos efectuados por los condenados en Sierra Chica y la descripción antropológica de los penados.

Con la mirada puesta en desarrollos actuales de la metodología de la investigación social, propongo reconstruir a partir de cuáles técnicas fueron producidos aquellos datos que refieren a las características de la Penitenciaría y de los penados. En otras palabras, e inspirado en la terminología empleada por Diego Galeano (2013), pensar desde el presente las huellas de la investigación empírica de los Estudios Carcelarios.

Este objetivo, así como el artículo en su conjunto, se inscribe en un punto de intersección entre dos áreas de interés y de desarrollo personales. Por un lado, mi práctica como docente de una cátedra de Metodología de la Investigación Social en la carrera de sociología de la Universidad de Buenos Aires. En general, desde la enseñanza de la metodología y desde los textos/manuales respectivos es todavía hábito frecuente no desplazarse demasiado tiempo atrás para indagar cómo distintos autores construyeron evidencia empírica en el pasado. A tal punto que incluso los denominados padres fundadores de la disciplina sociológica casi no son leídos en clave teórico-metodológica. La revisión que aquí propongo constituye una invitación a ampliar el rango temporal, incorporando a la historia como una protagonista más de la Metodología de la Investigación Social. Por el otro lado, Criminalogía Moderna constituye uno de los dominios empíricos relevados y analizados para mi tesis doctoral, la cual está centrada en la comparación de dos arcos temporales (1890-1915 y 1990-2015) en términos de los procesos de persistencia y ruptura de imaginarios estatales producidos por las instituciones policial y judicial acerca de los vínculos entre inmigración (europea y limítrofe, respectivamente) y delincuencia. Es en este sentido que el artículo se ubica en el cruce de mi trayectoria formativa, entre la práctica docente que llevo a cabo y mis temas de investigación de interés.

\section{Adentrándonos en las páginas de Criminalogía Moderna}

Con el objetivo de proveer observaciones vivas sobre el fenómeno de la criminalidad, en relación a las diversas causas que la determinan y a la profilaxis contra el delito, se inaugura, hacia noviembre de 1898, la publicación de Criminaloga Moderna. Caracterizada a posteriori como la primera revista criminológica argentina (Sozzo, 2011), se enmarca en el proceso de emergencia y consolidación de dicho campo de saber sobre la cuestión criminal, a nivel nacional, y más particularmente en la Ciudad y Provincia de Buenos Aires. Tal proceso se vinculó, como parte de algunos de sus hitos y vaivenes, a la inserción de la criminología en su vertiente positivista -y en un diálogo no exclusivo ni exento de críticas con exponentes de la Scuola Positiva italiana: Cesare Lombroso, Enrico Ferri, Raffaele Garofalo, entre otros- en ámbitos académicos, espacios institucionales y en el plano de diversas publicaciones a través de las cuales eran difundidas las ideas y nociones asociadas a esta corriente de pensamiento. De tal modo se podrían mencionar la creación, en el marco de la Universidad de Buenos Aires, de una cátedra exclusivamente dedicada al derecho criminal en 1887 (la cual adoptó como programa la enseñanza de los exponentes anteriormente mencionados); la inserción de autores positivistas en cátedras universitarias de Medicina Legal, Psicología y Sociología; la fundación de 
la Sociedad de Antropología Jurídica en 1888; la inauguración del Servicio de Observación de Alienados en 1900, posteriormente denominado Clínica Psiquiátrica y Criminológica de la Policía de la Capital; y la creación, en 1907, del Instituto de Criminología, dirigido por José Ingenieros y organizado al interior de la Penitenciaría Nacional.

Respecto al plano de la divulgación científica, este aspecto fue apuntado por distintos autores (Salvatore, 2000, 2010; Marteau, 2003; Caimari, 2004; Rodríguez, 2006; Creazzo, 2007; Scarzanella, 2015; Olaeta, 2018), quienes, posicionándose desde diversos intereses de investigación y con una fuerte impronta historiográfica, han referido a distintas publicaciones periódicas: Criminalogía Moderna, Archivos de Criminología, Medicina Legal, Psiquiatría y Ciencias Afines, Revista Argentina de Ciencias Políticas y Revista de Derecho. Historia y Letras. Entre ellos, Julia Rodriguez (2006) destaca un detalle del título de Criminalogía Moderna -que en gran parte se vincula con su contenido-, a saber: el uso intencional, por parte de los editores, del término criminología, con el objeto de enfatizar que se trataba de una ciencia del criminal, más que del crimen.

Tal como fue anteriormente mencionado, Criminalogía Moderna (en adelante, CM) fue dirigida por Pietro Gori, abogado y anarquista de origen italiano, quien arribó a Buenos Aires el 21 de junio de 1898 en calidad de exiliado. En un interesante texto sobre la estadía de Gori en Argentina, en términos de sus aportes y vicisitudes, Martín Albornoz (2014) lo destaca como una figura clave tanto en el campo de la política (a partir de la militancia anarquista en el movimiento obrero), como en la cultura científica porteña de fin de siglo, siendo definida la fundación de $C M$ como uno de sus más notables proyectos culturales en el país. Acompañando a Gori en la dirección de la revista, Ricardo del Campo se desempeñó primero como Secretario de Redacción y, luego, cediéndole ese lugar a Miguel Ángel Lancelotti, como Redactor en Jefe. Ambos contribuyeron sobremanera en la publicación, ya sea a partir de artículos sueltos firmados por ellos mismos -o en nombre de La Dirección y/o La Redacción-, como de secciones dedicadas a temáticas específicas.

En términos de su composición, distintos autores han enfatizado características acerca del staff de la revista. Así, Scarzanella (2015) destaca que la misma reunía los aportes de estudiosos italianos y argentinos. Por su parte, Rodriguez (2006) señala a CM como una colaboración entre abogados, criminólogos y médicos legistas argentinos y científicos europeos, aunque la autora menciona entre ellos únicamente a Ferri y Lombroso. Otro comentario al respecto es el que realiza Albornoz (2014), quien afirma: "Gori supo agrupar a un notable staff de colaboradores que daba cuenta, entre otras cosas, de una enorme versatilidad a la hora de tejer redes relacionales en tiempo récord" (p. 33).

Más allá de la apreciación personal de cada autor, lo cierto es que $C M$ contaba con colaboradores locales y extranjeros. La propia revista se ocupaba de darle publicidad a los mismos, incluyendo en la tapa de cada nuevo número la lista de todos ellos. 
FIGURA 1

Tapa de Criminalogía Moderna

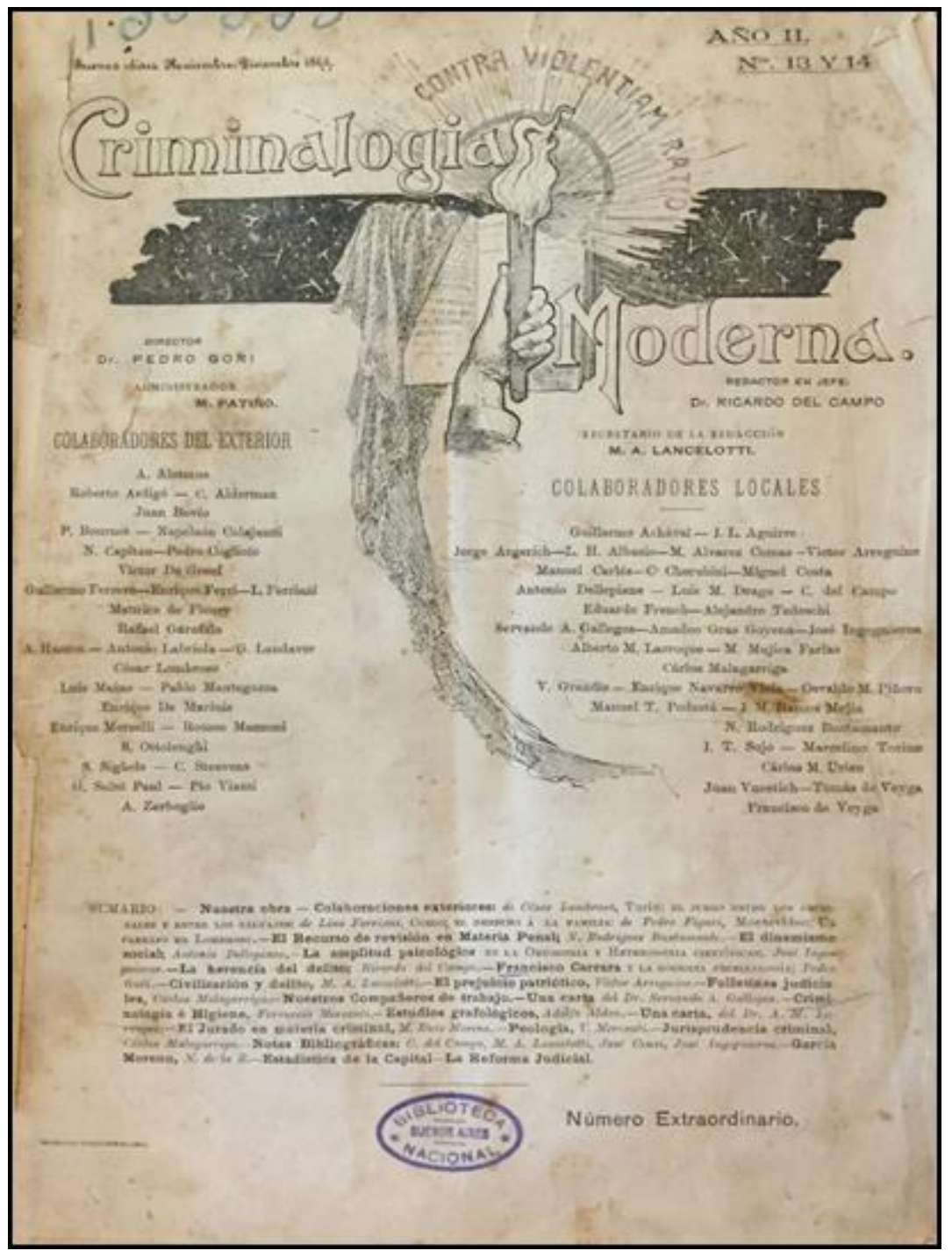

Criminalogía Moderna, año 2, n. ${ }^{\circ}$ 13-14, Buenos Aires, 1899. Recorte de fotografía tomada en la Hemeroteca de la Biblioteca Nacional

En lo que refiere a los colaboradores locales, provenían de diversas disciplinas e instituciones, podemos mencionar entre otros a Guillermo Achával, Francisco de Veyga, Antonio Dellepiane, Luis M. Drago, Víctor Arreguine, Manuel Carlés, Juan Vucetich y José Ingenieros, quien fuera colaborador desde junio de 1899.

Respecto a los colaboradores extranjeros, la revista contaba con profesores, abogados y catedráticos de distintas partes del mundo, tales como Cesare Lombroso, Enrico Ferri, Pedro Figari, Charles Aldermann, Scipio Sighele, Agustín Hamon, Napoleon Colajanni, Raffaele Garofalo y Guglielmo Ferrero.

Desde noviembre de 1898 a enero de 1901 fueron editados veintiún números de $C M$, totalizando una cantidad de seiscientos cincuenta y seis páginas. Radicada en Buenos Aires, se presentaba con periodicidad mensual, aunque ello se cumplió sobre todo en los dos primeros años de la revista, variando así la fecha de edición en los años 1900 y 1901, y dejando mucho más espacio en el intervalo entre número y número. Quizás el principal motivo de esta demora se haya debido a las dificultades financieras en la edición. De hecho, para Rodriguez (2006), la falta de fondos fue la causa principal de su desaparición hacia el año 1901.

En sus veintiún números editados, $C M$ orientó sus artículos a temas de derecho y procedimiento penal, sociología y antropología criminal, medicina legal, legislación y jurisprudencia. Algunos de estos temas 
coincidían con secciones permanentes específicas, como los casos de Crónica judicial y Jurisprudencia criminal. Con el soporte de la colaboración de Juan Vucetich, se incluía una sección dedicada particularmente a la estadística policial y carcelaria (titulada Cuadros demostrativos), así como Resumen trimestral de estadística de la Policía de la Provincia de Buenos Aires. Otras de las secciones permanentes de $C M$ eran Notas Bibliográficas (donde se publicaban reseñas y comentarios de libros y revistas, tanto locales como internacionales, y con la cual contribuían principalmente Pietro Gori, Ricardo del Campo, José Ingenieros y Miguel A. Lancelotti), Guía del Estudiante (una sección dedicada a reseñas bibliográficas de mayor detalle y extensión, centradas particularmente en las obras de Garofalo y Ferri) y Colaboraciones exteriores, especiales y exclusivas para Criminalogía Moderna, quizás una de las secciones más relevantes en tanto permite observar las contribuciones hechas por los distintos colaboradores extranjeros.

En algunos de los números editados se agregaron otras secciones, las cuales referían a distintos tópicos de interés tales como biografías y estudios positivos sobre las personalidades culminantes del mundo criminal, resúmenes de los procesos célebres universales y locales, juicio por jurados, necesidad de reforma de la justicia penal, pronunciamientos contra la pena de muerte... Al interior de este conjunto de secciones, que se reiteraban consecutivamente en más de un número de la revista, se inscriben los Estudios Carcelarios.

Un último comentario que merece hacerse acerca del contenido de $C M$ refiere al rol asignado a los recursos visuales, ya sea que se trate de ilustraciones, reproducciones fotográficas o litografías. En tal sentido, consultar las páginas de la revista ofrece un amplio muestrario de imágenes y maneras de retratar al homo criminalis, pero también a los autores más consagrados que allí colaboraban. Además, a través del lente de la cámara de Vucetich, se dieron a conocer diversos componentes visuales de la Penitenciaría de Sierra Chica, aspecto sobre el cual volveré luego.

Con respecto al acceso a la fuente, la lectura de Estudios Carcelarios fue realizada a partir de la descarga directa desde la web, ya que algunos números de $C M$ se encuentran -desde el año 2012- alojados en la Biblioteca Digital de la Corte Suprema de Justicia de la Nación (https://bibliotecadigital.csjn.gov.ar/revis $\operatorname{tas} /)$.

\section{Los Estudios Carcelarios...}

Editados entre abril y junio de 1899 , fueron presentados como los apuntes del viaje de estudio que Gori emprendió, junto a Vucetich, a la Penitenciaría de Sierra Chica. A partir de otras experiencias, podría sostenerse que la visita a las cárceles constituía todo un género en la literatura criminológica de la época.

Al respecto, Luis González Alvo y Jorge Núñez (2014) describen el itinerario realizado por distintos "viajeros penitenciarios", motivados por una fuerte impronta reformista. Josh Howard y su recorrido por las instituciones de reclusión europeas, realizado en el último cuarto del siglo XVIII; Alexis de Tocqueville y Gustave de Beaumont, quienes fueron enviados por el gobierno francés -entre abril de 1831 y enero de 1832para estudiar el sistema penitenciario estadounidense; las experiencias de Ramón de la Sagra tras su recorrido por Estados Unidos (1835); y las visitas emprendidas por el jurista rosarino Adolfo S. Carranza a cárceles europeas en 1921, con miras a ampliar sus conocimientos sobre los diferentes regímenes penitenciarios del mundo, y contribuyendo, de esa manera, a llevar a cabo la reforma en Tucumán.

En otro texto, Núñez (2014) destaca particularmente los viajes de Fernando Cadalso a Estados Unidos en 1910 ("tour" penitenciario en el marco del VIII Congreso Penitenciario Internacional de Washington) y entre los años 1912 y 1913. En este texto estudió -financiado por la Junta para Ampliación de Estudios e Investigaciones Científicas- las instituciones penitenciarias, a partir de lo cual "importó" un modelo que aplicó con éxito en España (concretamente, en el Reformatorio de Adultos de Ocaña). A la vez, menciona igualmente otras experiencias de viajes de españoles a cárceles situadas en otros países de Europa: el de Francisco Cabrerizo García a Londres, el de Álvaro Navarro de Palencia a Italia, Francia y Bélgica, y el de Diego Romero de Aguilar, a estos dos últimos países. 
En más de una ocasión, los autores mencionados destacan la importancia que tiene esta temática dentro de la historiografía social; de hecho, González Alvo y Núñez (2015) señalan la indagación de los "viajeros penitenciarios" como parte de una agenda de trabajo de la historia de la prisión en Argentina, para el periodo comprendido entre 1860 y 1950.

Por su parte, Scarzanella (2015) relata las crónicas de las visitas efectuadas por autores italianos, vinculados a la Scuola Positiva, a la Penitenciaría Nacional de Buenos Aires, haciendo explícita referencia a Gina Lombroso, Guglielmo Ferrero y Enrico Ferri. Como modo posible de profundizar en las impresiones de sus visitas, estas fueron editadas -ya sea en forma extensa o breve, desde una perspectiva crítica o más bien elogiosa- en Archivos de Psiquiatría, Criminología, Medicina Legaly Ciencias Afines, una de las publicaciones más significativas del campo del saber criminológico, dirigida por José Ingenieros entre 1902 y 1913 (Ferri, 1908; Ferrero, 1908; Lombroso, 1908).

La Penitenciaría Nacional fue también objeto de visita y estudio por parte de Eusebio Gómez, otro destacado criminólogo argentino, quien detalló sus impresiones en Estudios penitenciarios (1906). Acorde al objetivo que propongo abordar en el presente artículo, resulta significativo mencionar que un capítulo de dicho libro está dedicado a las observaciones realizadas en la Penitenciaría de Sierra Chica. Allí, el autor presenta una mirada ciertamente negativa, en relación a distintos aspectos: carece de todos los requisitos necesarios para encuadrar dentro de los preceptos de la ciencia penitenciaria, hay un exceso de penados, la pederastia es el vicio imperante, los penados son embusteros, perezosos, habladores, llenos de una elocuencia de mala ley -y de los cuales no puede asegurarse que no reincidirán-, negación de la instrucción e inexistencia de trabajo organizado y, como componente visual, el uniforme de los penados es concebido como un recurso verdaderamente perjudicial para su salud moral; todo lo cual sintetiza Gómez (1906) al referirse a Sierra Chica como "aquella casa maldita" (p. 60).

Las visiones negativas de este autor acerca de Sierra Chica van a reiterarse, como bien lo señalan Hernán Olaeta y Juan José Canavessi (2019), en el primer Congreso Penitenciario Nacional, realizado en mayo de 1914 en Buenos Aires, y que tuvo, como parte de sus actividades, las visitas a dicha prisión y a la Penitenciaría Nacional. Un aspecto que plantea la posibilidad de realizar - para una indagación ulterior- un contrapunto entre las miradas de Gori y Gómez, poniendo en diálogo los Estudios Carcelarios, la descripción realizada en Estudios Penitenciarios,y lo expresado en los Trabajos y Actas del Congreso Penitenciario Nacional (Gómez, 1914).

Por el momento, dirijámonos a Sierra Chica desde el viaje de estudio emprendido por Gori, en compañía de Juan Vucetich. Con respecto a los hitos en la trayectoria biográfica de este último, Mercedes García Ferrari (2010, 2015) señala que, en ese entonces, se desempañaba como director de la Oficina de Estadística, en el marco de la cual llevaba adelante la publicación del Boletín de Estadística, y de la Oficina de Identificación Antropométrica - desde donde comenzó a implementar, a partir de 1891, el Sistema Dactiloscópico Argentino que lo volvió mundialmente reconocido-, ambas dependencias formaban parte de la Policía de la Provincia de Buenos Aires. Para la autora (García Ferrari, 2015), la labor realizada en la década de 1890 lo posicionaba a Vucetich "como un referente regional en la naciente estadística criminal y en los nuevos métodos de identificación a través de la fotografía, las medidas corporales o las impresiones digitales” (p. 41).

Tal viaje es presentado como el puntapié inicial de una investigación carcelaria-antropológica, o como el propio Gori (1899a) lo define:

Una peregrinación melancólica e interesante al mismo tiempo, a través de las casas y colonias penales de la República, para estudiar el sistema carcelario de la Argentina y a su vez la población dolorosa que en aquellos sitios se aglomera (p. 176).

La sección fue publicada, de manera desagregada, en cuatro artículos, cada uno de los cuales estuvo orientado a una determinada temática.

En el primero, se desplegaron distintas características externas e internas de la Penitenciaría. La ubicación geográfica y la estructura arquitectónica, así como el recorrido que lleva a los visitantes a la entrada, son 
señaladas como características externas. Estas son contadas con gran detalle, en una invitación de Gori a los lectores a imaginarnos ingresando a los pabellones. En relación a las características internas, el autor hizo referencia crítica a componentes visuales en la organización de la institución: más específicamente, a la vestimenta - de color rojo- de los detenidos, a la práctica de los aniversarios del delito y a la mezcla de los individuos condenados. En relación a ello, señalaba que los condenados políticos y los delincuentes comunes estaban ubicados en las mismas galerías y con el mismo tratamiento disciplinario. Por fuera de aquellos comentarios críticos, el primer artículo de Estudios Carcelariosculmina con halagos hacia la figura de Miguel Costa, director de la Penitenciaría, al ser destacadas las innovaciones prácticas que introdujo. El grado de detalle del texto de Gori es complementado por una fuerte y vigorosa presencia del recurso visual: fotografías tomadas por Vucetich y reproducidas en las páginas de $C M$, un aspecto que estará presente en la sección en su conjunto.

Continuando el recorrido por la Penitenciaría, en el segundo artículo se destacaron distintos aspectos acerca de los trabajos que allí realizaban los penados, tanto en relación a los ámbitos espaciales donde se hacían (talleres de ebanistería, carpintería, herrería, entre otros), como a partir del detalle de las actividades llevadas a cabo. En clara continuidad con el artículo inaugural de Estudios Carcelarios, Gori acompañaba su relato detallado con comentarios críticos, ilustrativamente al referir a la inutilidad del aislamiento celular y a los problemas existentes -en materia de mayor oferta laboral y mejor infraestructura- entre el gobierno de la provincia y la dirección de la institución penitenciaría.

Finalmente, los últimos dos artículos de la sección pertenecen a aquello que Gori (1899c) definió: "La parte más controvertida e interesante en los estudios de este género: la relación directa entre las diversas penas y las distintas clases de criminales a quienes les son aplicadas" (p. 228).

Si bien la sección es titulada Estudios Carcelarios, la Penitenciaria de Sierra Chica es concebida, en estos últimos artículos, como un contexto idóneo para estudiar a los criminales, cuya clasificación fue uno de los tópicos que más ha dado lugar a discusiones y controversias dentro de la matriz común de la criminología positivista. Al circunscribir su interés por el delincuente que puede ser conocido en la cárcel, Gori contribuye a un equívoco que Massimo Pavarini (2010) planteó para dicho campo de saber: la estrecha equiparación entre delincuente y encarcelado.

Al delimitar como objeto de estudio a la población encarcelada, es relevante destacar que lo que Gori pretende indagar y conocer, aquello sobre lo cual quiere producir conocimiento, está orientado por su adhesión al positivismo criminológico. $\mathrm{Al}$ respecto, podría sintetizarse del siguiente modo, a partir de lo expuesto por Lila Caimari (2004), la doble identidad de Gori como "viajero penitenciario" y criminólogo, movilizado tanto por conocer la situación carcelaria del país como por la "ciencia de la transformación":

Gori combinaba su interés en Lombroso con un compromiso activo con el proyecto penitenciario: de él denunciaba los aspectos más ignominiosos, como el uniforme infamante de los penados de ciertas prisiones y la práctica de reclusión solitaria, pero hacía suyos todos sus preceptos disciplinarios (p. 95).

Más particularmente, Gori parte de la afirmación según la cual no existe el criminal prototipo - "triunfo" constatado por la antropología criminal- sino diversos tipos de delincuentes. Al respecto, sus observaciones están guiadas por categorías conceptualmente construidas desde esa perspectiva o campo de saber: delincuencia sexual, degeneración monstruosa, locura moral, gauchos malos, monstruos morales, delincuentes por hábito adquirido, criminales acrocéfalos, entre otras ${ }^{1}$. En la presentación de aquellos casos considerados dignos de mención, el énfasis radicaba en una descripción antropológica centrada en aspectos fisionómicos, en el menor o mayor desarrollo de ciertas cualidades o facultades, la mayor o menor atrofia del sentido moral y en la influencia de los factores o causas que -sean individuales o sociales- operaban en la comisión del delito. Esta descripción era complementada, a su vez, con un retrato fotográfico tomado por el propio Vucetich; aunque Gori destacó ocasiones en que existieron dificultades técnicas que impidieron su reproducción, especialmente en relación a los negativos de las fotografías. 


\section{4. ...LEÍDOS EN CLAVE TEÓRICO-METODOLÓGICA}

Retomando el argumento de Ricardo Salvatore (2013), según el cual en La mala vida en Buenos Aires "es notable no sólo lo que Gómez dice sobre la delincuencia, las anomalías morales y el vicio, sino también cómo llega a estas afirmaciones" (p. 115), propongo reconstruir las técnicas a partir de las cuales fueron producidos los datos presentados en los Estudios Carcelarios.

Ya en el artículo inaugural de dicha sección, Gori señalaba las actividades que realizó durante su viaje de estudio, enmarcadas en su objetivo de estudiar el sistema carcelario de la Argentina y a la población encerrada: consultar documentos e interrogar con sumo interés a aquellos presos que eran considerados por él como dignos de mención. En términos de una lectura teórico-metodológica, dichas actividades se encuentran agrupadas en la definición de observación participante de Norman Denzin, la cual retoma Uwe Flick (2012) del siguiente modo: "Una estrategia de campo que combina simultáneamente el análisis de documentos, la entrevista a respondientes e informantes, la participación directa y la observación, y la introspección” (p. 154).

Más aún, un señalamiento realizado en el tercero de los artículos, particularmente en torno a la clasificación de los delincuentes, nos aporta otra pista para aproximarnos a las maneras en que fueron construidos los datos que Gori dio a conocer en Estudios Carcelarios: "Ocho días de estudio y observaciones asiduas [con el propósito de] establecer comparaciones entre los diversos casos, bajo el punto de vista de los documentos oficiales" (Gori, 1899c, p. 229).

Siguiendo la clasificación expuesta por Flick (2012), se podría destacar que, en la indagación sobre los distintos aspectos de la Penitenciaría de Sierra Chica y de los penados, fueron utilizados tanto métodos visuales como verbales, enmarcados en la investigación cualitativa.

Una de las técnicas de producción más paradigmáticas del primer conjunto es la observación, la cual es definida por Adrián Scribano (2008) como "una técnica específica para obtener información sistemática del mundo social” (p. 55). A su vez, señala dos de los rasgos que vinculan a la técnica y al investigador social entre sí: la virtual participación en lo que se trata de comprender y la capacidad de comunicarse con los sujetos involucrados en los fenómenos que se estudian. Ambos rasgos se encuentran presentes en la indagación realizada por Gori, en el sentido de que su visita a la Penitenciaría fue una ocasión para compartir espacios comunes con la población allí encerrada, así como por la posibilidad de acercarse y entablar conversaciones con los penados. A modo de ilustración, en el segundo de los artículos de Estudios Carcelarios(Gori, 1899b), es detallada una de estas escenas dialógicas realizada a partir de una observación; en el recorrido que, en ese entonces, estaban efectuando Gori, Vucetich y el director de la Penitenciaría por los talleres donde los reclusos trabajaban, el primero de ellos entabla una conversación al acercarse y preguntarle a un ebanista si tenía familia.

En el mismo sentido, las decisiones que tomó en el desarrollo del trabajo de campo, así como las actividades llevadas a cabo, pueden incluirse dentro de las siguientes fases de observación (Flick, 2012):

- La selección de un entorno: dónde y cuándo se pueden observar los procesos y las personas interesantes

- La definición de lo que se debe documentar en la observación y en cada caso

- Las observaciones descriptivas, que proporcionan una presentación inicial del campo

- Observaciones selectivas, que se pretende que capten deliberadamente sólo aspectos centrales

De esta manera, Gori proporcionó observaciones descriptivas del lugar, en tanto se constituía como un espacio físico diferente a otros, con una estructura y características arquitectónicas particulares, expresando detalladamente en palabras y esquemas aquello que el recorrido por la Penitenciaría le facilitó mirar. Desde otra perspectiva, Scribano (2008) presenta algunas preguntas vinculadas a dicha descripción, las cuales pueden constituir una interesante grilla de lectura teórico-metodológica del primer artículo de Estudios Carcelarios: ¿Cómo es el contexto? ¿Cómo está distribuido el espacio físico? ¿Cómo cambia la situación de 
acuerdo con los diferentes lugares observados? ¿Cuáles son las similitudes y diferencias con otros espacios? Otro de los ejes de la observación, e indudablemente uno al que se le dedicó vasta atención, es el de los recluidos: quién o quiénes estaban en la escena observada, cuántos eran y por qué se encontraban allí.

$\mathrm{Al}$ respecto, el propio Gori (1899c) presentó, en el tercero de los artículos de Estudios Carcelarios,una de esas escenas que involucraban al observador y al observado: "Lo miraba por el orificio de la cerradura colocada en la puerta de la celda, mientras vestía el hábito rojo de la infamia. Estaba solo y no sospechaba seguramente que era observado por mí, con honesta curiosidad científica" (p. 230).

Paralelamente a las observaciones descriptivas acerca de la Penitenciaría y los penados, es posible señalar aquellas observaciones que -leídas desde lo expuesto por Flick- podemos definir como selectivas: ilustrativamente, al referirse a aspectos centrales tales como la realización de una misa y los trabajos realizados por los reclusos. En estos casos, podemos resaltar que el eje no estaba puesto tanto en quiénes eran los que participaban de la escena de observación, cuanto las interacciones suscitadas entre sí, especialmente en aquellos momentos en que los penados compartían lugares en común.

Desde otra arista, los Estudios Carcelariospueden ser indagados a partir de las distintas dimensiones de observación: lugar físico, personas implicadas, emociones expresadas, actividades realizadas, acciones individuales, y secuencia en el tiempo.

En términos de las características generales de la técnica de observación, Scribano (2008) afirma, por su parte, que uno de los aspectos a tener en cuenta consiste en estar alerta respecto de las conversaciones. En ese sentido, apuntala distintas preguntas: ¿Cuál es el contenido de las conversaciones? ¿Quién le habla a quién? ¿Quién escucha? Ese estado de alerta acerca de lo que se enuncia puede ser reconstruido igualmente en otra de las escenas relatadas por Gori (1899c):

Una mañana que en compañía del Director y del Sr. Vucetich, volvía a proseguir estos estudios sobre los penados, al pasar bajo la ventanilla de una celda, oímos reír alegremente a los dos reclusos que se encontraban en ella, con motivo de los picantes detalles referidos por uno de ellos a su compañero, con la jactancia característica de las confidencias recíprocas entre los penados, sobre una violación llevada a cabo por él, en persona de una mujer vieja (p. 231).

La importancia de este fragmento es tal que lleva al autor a desplazarse desde la observación a otra técnica cualitativa de producción de datos, la entrevista.

Antes de adentrarnos en ella, resulta relevante mencionar la utilización de otro método visual de producción de datos: la utilización de fotografías con fines de investigación. Más detalladamente, y en línea con la lectura que propongo en este artículo, las fotografías son definidas por Flick (2012) como fuentes de datos. Siguiendo a Barthes, el autor establece distintos tipos de relación entre el investigador y el investigado. En el caso de Estudios Carcelarios, el operador que toma la fotografía (el compañero de viaje de Gori, Juan Vucetich) puede utilizar al individuo investigado como modelo: dar a conocer los retratos fotográficos de los reclusos como manera de observar en ellos sus características más particulares y notorias, y que - desde una apropiación teórica de las ideas de Lombroso y de otros autores afines de la Scuola Positiva- lo habilitarían a Gori a clasificarlos en distintas "familias criminales". O para expresarlo desde las propias páginas de $C M$, dichos retratos son presentados como un complemento respecto a la descripción antropológica realizada en torno a los penados. 


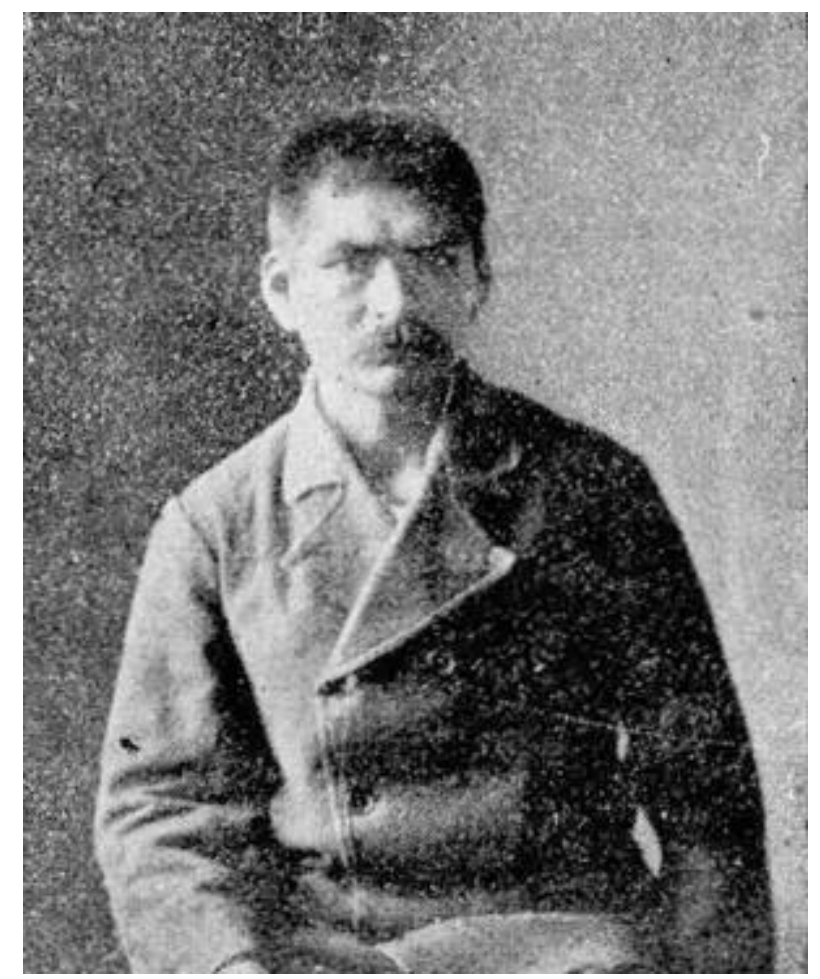

FIGURA 2

Retrato de un penado de Sierra Chica.

Gori (1899c). Extraída de la Biblioteca Digital de la Corte Suprema de Justicia de la Nación.

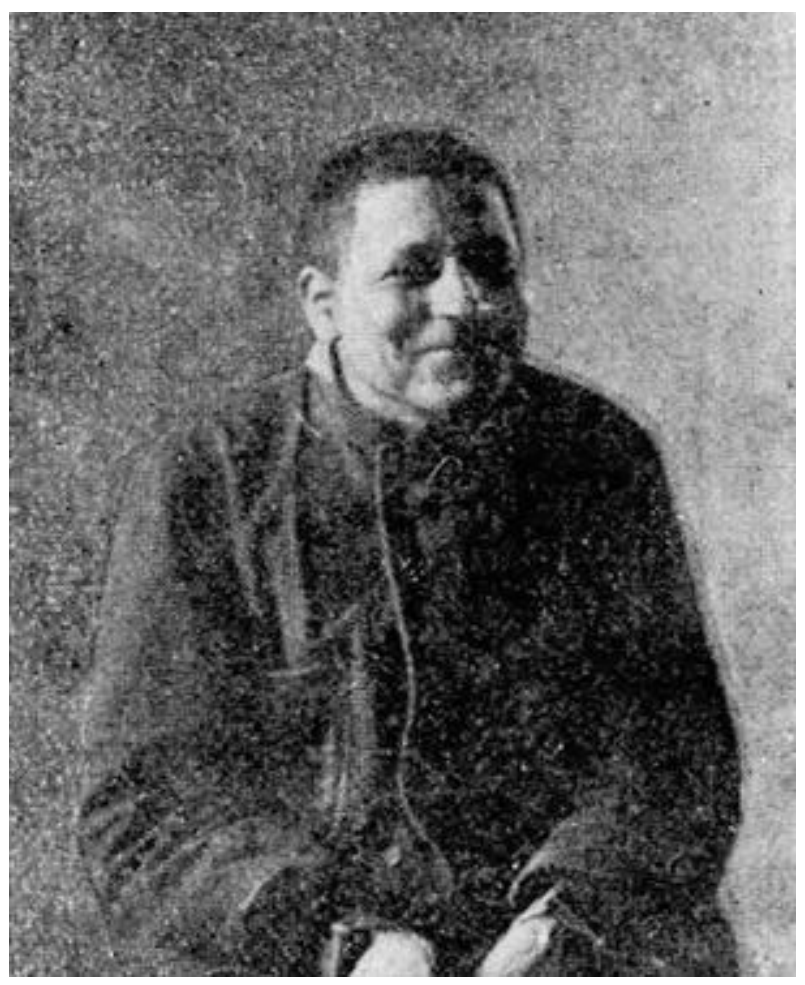

FIGURA 3

Retrato de un penado de Sierra Chica.

Gori (1899d). Extraída de la Biblioteca Digital de la Corte Suprema de Justicia de la Nación. 
No resulta azarosa la selección del formato del retrato, dado el extendido uso institucional de la fotografía como tecnología de identificación policial (García Ferrari, 2010); recordemos, al respecto, que quien fotografiaba a los reclusos de Sierra Chica se desempeñaba en el ámbito de la Policía de la Provincia de Buenos Aires.

Pero también la fotografía estaba puesta al servicio de la reproducción de los sitios y lugares de la Penitenciaría. Al respecto, al recorrer los distintos lugares donde trabajaban los penados, Gori (1899b) señalaba: "Cuando llegamos, en compañía del Director, a la vegetación exuberante de la quinta, vimos surgir, como una inexorable persecución científica, la máquina fotográfica del Sr. Vucetich” (p. 210).

De este modo, la relación entre investigación y fotografía era así planteada desde la perspectiva del autor de Estudios Carcelarios.

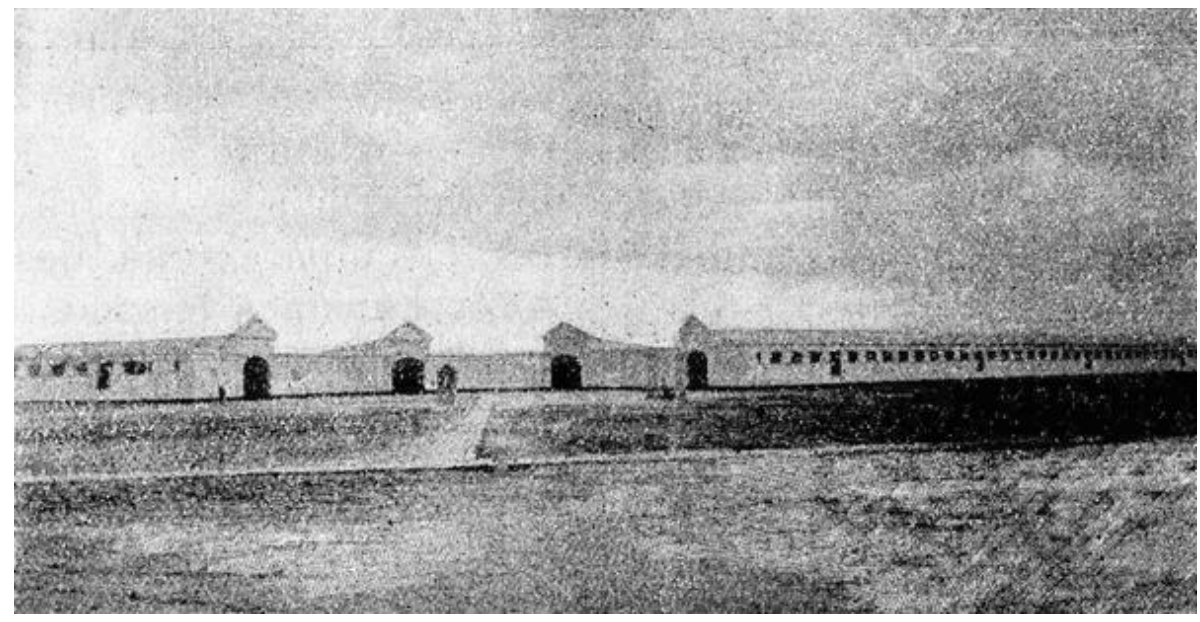

FIGURA 4

Fotografía de la Penitenciaría de Sierra Chica.

Gori (1899a). Extraída de la Biblioteca Digital de la Corte Suprema de Justicia de la Nación.

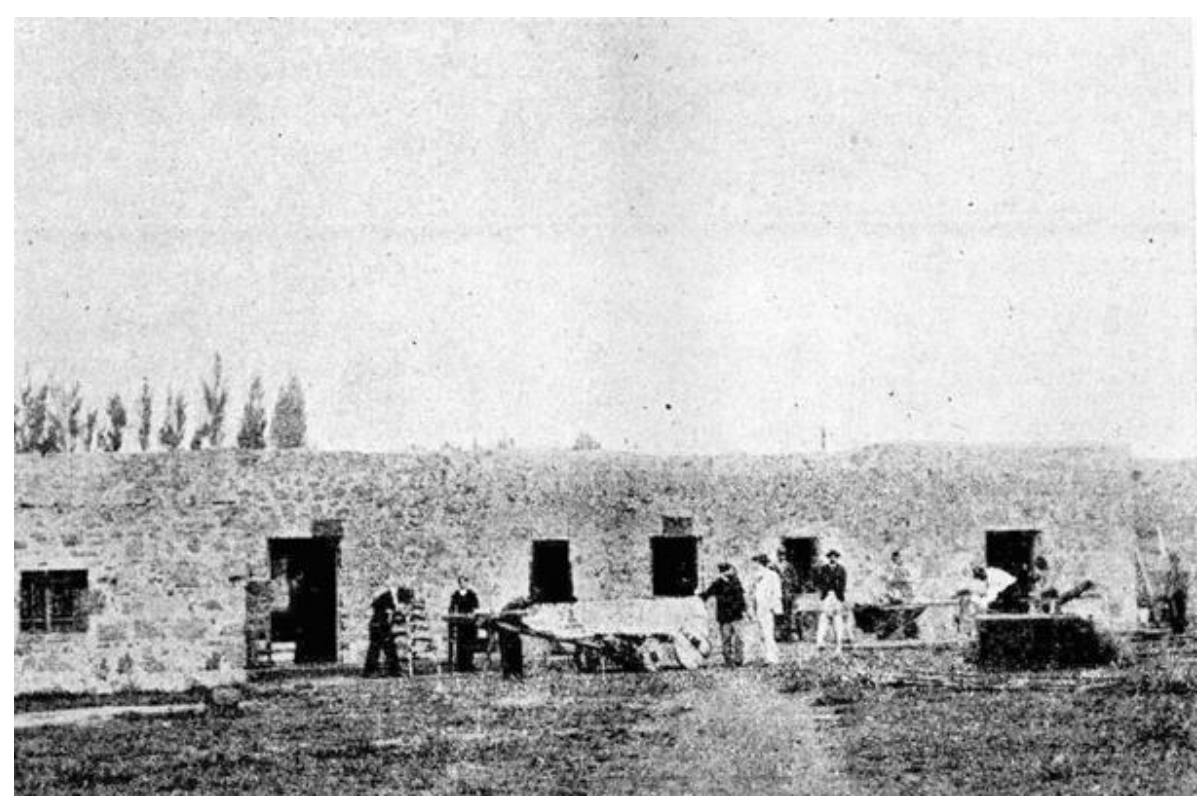

FIGURA 5

Fotografía de los penados trabajando.

Gori (1899b). Extraída de la Biblioteca Digital de la Corte Suprema de Justicia de la Nación.

Tal como fue mencionado con anterioridad, Gori no se valió únicamente de métodos visuales para la producción de los datos, sino también verbales. A partir de los relatos presentados en los cuatro artículos que 
componen la susodicha sección, se podría señalar la implementación de entrevistas a distintos informantes clave: más particularmente, al Director de la Penitenciaría y a algunos de los penados, aquellos que fueron considerados por él dignos de mención. De esta manera, produjo datos formulando preguntas acerca de acciones, opiniones y representaciones (Scribano, 2008). Aunque es preciso destacar que a diferencia de la técnica de entrevista, donde existe un acuerdo mutuo pautado entre entrevistado y entrevistador, Gori (1899c) entabló conversaciones con los penados a partir de la práctica reglamentada del interrogatorio, convirtiendo a la misma en "un experimento de psicología carcelaria” (p. 231).

Debido a este aspecto, podemos clasificar la práctica realizada por Gori -desde la Metodología de la Investigación Social- como un ejemplo de entrevista clínica (Scribano, 2008).

En términos del contenido que se busca, podríamos referirnos a la técnica de entrevista narrativa, en el sentido de que "puede dirigirse a un aspecto especifico, temporal y temático de la biografía del informante" (Flick, 2012, p. 111), básicamente a aquellos hechos que atañen a la comisión del delito. De este modo, se puede sostener que Gori presentaba los testimonios producidos por los entrevistados como un dato que permitiría clasificarlos en distintas categorías de delincuentes. Alternativamente, podríamos leer teórico-metodológicamente los Estudios Carcelarios a partir de la entrevista episódica, la cual comparte los rasgos de la entrevista narrativa, aunque dispone de un mayor grado de estructuración y guía por parte del entrevistador. Se encuentra asimismo asociada a situaciones y circunstancias concretas. Así es como Gori (1899d) invitaba a aquellos penados, considerados dignos de mención, a narrar los acontecimientos que giraban en torno a los hechos delictivos cometidos:

Gregorio Magallanes, el $n^{\circ} 167$, argentino, condenado, también por tiempo indeterminado, por varios asesinatos, el primero de los cuales que me fue narrado por él con los más espantosos detalles y con toda indiferencia, es el mejor documento de psicología criminal que puedo presentar, de este recluso (...) Al hacer la narración del hecho, vagaba entre sus labios una sonrisa idiota de ferocidad que causaba repugnancia. Y mientras hablaba, agitaba sus monstruosas mandíbulas simianas, dejando escapar de la boca entre una y otra palabra, como pequeños rugidos sofocados (p. 269).

Aunque en ocasiones esta forma de acercamiento no fue exitosa, hay pistas suficientes para tematizar que los relatos reproducidos en las páginas de $C M$ fueron obtenidos por medios de entrevistas realizadas por Gori, las cuales podemos clasificar desde el presente como clínicas, narrativas o episódicas.

Para concluir, resulta conveniente señalar que, más allá de la importancia en los métodos utilizados por el autor para describir las características de la Penitenciaría de Sierra Chica y de los penados, los Estudios Carcelariostambién proporcionan un ejemplo de que no se trata exclusivamente de un empirismo radical. Seguimos, en ese sentido, lo expuesto por Diego Galeano (2013): “que los criminólogos hayan sostenido un diálogo estrecho y complejo con sus referentes empíricos no significa que sus miradas estuvieran libres de esquemas cognoscitivos y prejuicios morales estructuradores de la observación” (p. 269). Así, podemos leer los Estudios Carcelarios - fragmento de psicología criminal y carcelaria, tal como Gori se refiere a ellos- no únicamente en clave teórico-metodológica de las técnicas de producción de datos, sino también a partir de las discusiones, en el terreno conceptual, que entablaba el autor: desde las categorías teóricas que puso en juego en la descripción de lo observado, preguntado y consultado. A modo de ejemplo, la relación entre delincuencia y uso de tatuajes, discutiendo ni más ni menos que con Cesare Lombroso: en sus propias palabras, Gori (1899c) expresaba que "la hipótesis de Lombroso acerca del valor que debe atribuirse a este indicio, no tiene en Sierra Chica una seria comprobación” (p. 233).

Pero donde más se hacen patentes esos esquemas cognoscitivos que guían la observación de los referentes empíricos es en la clasificación del delincuente: los casos retratados -tanto antropológica como fotográficamente- son dignos de mención por su encasillamiento, desde la propia perspectiva del autor o la de aquellos aledaños, en determinadas categorías conceptuales: delincuencia sexual, locura moral, monstruos morales, delincuentes por hábito adquirido, criminales acrocéfalos... En este sentido, la lectura de Estudios Carcelarioscontribuye a que podamos enfatizar que no existe una disociación entre teoría y método, cada uno de ellos no constituye dos mundos separados sino mutuamente interrelacionados entre sí (Cohen y Gómez 
Rojas, 2019): el proceso de investigación involucra un camino de ida y vuelta entre las técnicas de producción utilizadas -métodos visuales y verbales en torno a la Penitenciaría de Sierra Chica y a los penados- y las problemáticas teóricas en las cuales Gori se orientó, que podemos sintetizar en el objetivo con el cual culmina la sección: contribuir al estudio de la delincuencia, como una necesidad de prevención contra el delito.

De esta manera vemos que la orientación teórica presente en Estudios Carcelarios es asimismo una orientación política; la criminología, en tanto conocimiento del criminal, un saber encauzado hacia un fin práctico. La lectura de esta sección permite identificar cuáles herramientas metodológicas se utilizaban para producir evidencia empírica de la cuestión criminal en el marco de un gobierno -con eje en la prevención del delito-; una relación que fue señalada por Pavarini (2006), al afirmar que toda criminología se tradujo en práctica criminológica perteneciente al campo de las respuestas a las demandas de orden social y de protección contra la criminalidad. O igualmente por Sozzo (2006), al definir a la criminología como "una ciencia política [que] tiene como centro de referencia la actividad de gobernar, de gestionar individuos y poblaciones" (p. 354).

Por último, e inspirándome en la propuesta de Cesano, Núñez y González Alvo (2019), resulta relevante que nos preguntemos por el lugar que tuvieron los Estudios Carcelarios en un espacio más amplio de circulación de saberes en materia penitenciaria y de viajes emprendidos por intelectuales, ya sean locales o extranjeros, para visualizar distintas experiencias carcelarias. De tal modo, no solamente se podría efectuar una lectura teórico-metodológica del viaje de estudio emprendido por Gori y Vucetich, sino describir sus vínculos y puentes con otros itinerarios que atravesaron igualmente distintas ideas en torno a la cuestión criminal y diversas técnicas para producir datos al respecto.

\section{Agradecimientos}

Agradezco los comentarios que hicieron Esteban González y Máximo Sozzo a una versión preliminar de este texto.

\section{ReFERENCIAS}

Albornoz, M. (2014). Pietro Gori en la Argentina(1898-1902): anarquismo y cultura. En P. Bruno (Org.), Visitas culturales en la Argentina, 1898-1935 (pp. 23-47). Buenos Aires: Biblos.

Caimari, L. (2004). Apenas un delincuente. Crimen, castigo y cultura en la Argentina, 1880-1955. Buenos Aires: Siglo XXI.

Cesano, J. (2012). Cornelio Moyano Gacitúa: su pensamiento en la tradición criminológica Argentina (1899-1905). En C. Moyano Gacitúa (2012 [1905]), La delincuencia argentina ante algunas cifras y teorias (pp. 11-45). Córdoba: Buena Vista Editores.

Cesano, J., Núñez, J. y González Alvo, L. (2019). Introducción. En J. Cesano, J. Núñez y L. González Alvo (Eds.), Historia de las prisiones sudamericanas. Entre experiencias locales e historia comparada (siglos XIX y XX) (pp. 9-25). San Miguel de Tucumán: Instituto de Investigaciones Históricas Leoni Pinto.

Cohen, N. y Gómez Rojas, G. (2003). Triangulando en torno al problema de investigación, los objetivos y el marco conceptual. En G. Gómez Rojas y S. Lago Martínez (Comp.), En torno a las metodologias: abordajes cualitativos y cuantitativos (pp. 113-127). Buenos Aires: Editorial Proa XXI.

Cohen, N. y Gómez Rojas, G. (2019). Acerca de la medición y el dato. En Metodología de la Investigación, ¿para qué? La producción de los datos y los diseños (pp. 15-38). Buenos Aires: Teseo.

Creazzo, G. (2007). El positivismo criminológico italiano en la Argentina. Buenos Aires: Ediar.

Ferrero, G. (1908). Europa y América. Archivos de Psiquiatría, Criminología, Medicina Legal y Ciencias Afines, 7 , 217-223. 
Ferri, E. (1908). De «la Scuola Criminale Positiva». Archivos de Psiquiatría, Criminología, Medicina Legal y Ciencias Afines, 7, 237.

Flick, U. (2012). Introducción a la investigación cualitativa. Madrid: Morata.

Galeano, D. (2013). Civilización y delito: Notas sobre cuatro criminólogos argentinos. Revista de Historia del Derecho, 45, 265-277. Recuperado de http://www.scielo.org.ar/scielo.php?script=sci_arttext\&pid=S18531784201300 0100009\&lng=es\&tlng=es

García Ferrari, M. (2010). Ladrones conocidos/sospechosos reservados. Identificaciónpolicialen Buenos Aires, 1880-1905. Buenos Aires: Prometeo.

García Ferrari, M. (2015). Marcas de identidad. Juan Vucetich y el surgimiento transnacional de la dactiloscopia (1888-1913). Rosario: Prohistoria.

Gómez, E. (1906). El presidio de Sierra Chica. En Estudios penitenciarios (pp. 55-67). Buenos Aires: Talleres Gráficos de la Penitenciaría Nacional.

Gómez, E. (1914). Visita al presidio provincial de Sierra Chica. En Trabajosy Actas del Congreso Penitenciario Nacional (pp. 302-303). Buenos Aires: Talleres Gráficos de la Penitenciaría Nacional.

González Alvo, L. y Núñez, J. (2014). Los viajes de estudio de Adolfo S. Carranza y la reforma penitenciaria en Tucumán (1911-1927). Revista de Historia del Derecho, 48, 121-141.

González Alvo, L. y Núñez, J. (2015). El porvenir del pasado penitenciario. Sobre la construcción de una agenda de trabajo para la historia de la prisión en la Argentina (1860-1950). Max Planck Institute for European Legal History Research Paper Series, 2015-06. Disponible en: https://ssrn.com/abstract=2648960

Gori, P. (1899a). Estudios Carcelarios. Una visita a la Penitenciaría de Sierra Chica. I. La Penitenciaría. Criminalogía Moderna, 2(6), 176-182.

Gori, P. (1899b). Estudios Carcelarios. Una visita a la Penitenciaría de Sierra Chica. II. Los trabajos. Criminalogía Moderna, 2(7), 205-212.

Gori, P. (1899c). Estudios Carcelarios. Una visita a la Penitenciaría de Sierra Chica. III. Los penados. Criminalogía Moderna, 2(8), 228-233.

Gori, P. (1899d). Estudios Carcelarios. Una visita a la Penitenciaría de Sierra Chica. III. Los penados. Conclusión. Criminalogia Moderna, 2(9), 263-269.

Lombroso, G. (1908). Instituciones americanas. La Penitenciaría Nacional de Buenos Aires. Archivos de Psiquiatría, Criminologia, Medicina Legal y Ciencias Afines, 7, 232-236.

Marteau, J. (2003). Las palabras del orden. Proyecto republicano y cuestión criminal en Argentina (Buenos Aires: 1880-1930). Buenos Aires: Editores Del Puerto.

Núñez, J. (2014). Los viajes a los Estados Unidos. En Fernando Cadalso y la reforma penitenciaria en España (pp.195-239). Madrid: Universidad Carlos III de Madrid.

Olaeta, H. (2018). La construcción cientifica de la delincuencia. El surgimiento de las estadísticas criminales en la Argentina. Bernal: Universidad Nacional de Quilmes.

Olaeta, H. y Canavessi, J. (2019). Los saberes penitenciarios. Análisis comparativo de los congresos penitenciarios realizados en 1914, 1953 y 1954 en la República Argentina. Revista de Historia de las Prisiones, 8, 22-56.

Pavarini, M. (2006). ¿Vale la pena salvar a la criminología?. En M. Sozzo (Coord.), Reconstruyendo las Criminologías Criticas (pp. 15-42). Buenos Aires: Ad-Hoc.

Pavarini, M. (2010). Control y dominación. Teorías criminológicas burguesas y proyecto hegemónico. México: Siglo XXI.

Rodríguez, J. (2006). Civilizing Argentina. Science, medicine and the modern state. Chapel Hill: University of North Carolina Press.

Salvatore, R.D. (2000). Criminología positivista, reforma de prisiones y la cuestión social/obrera en Argentina. En J. Suriano (Ed.), La cuestión social en Argentina, 1870-1943 (pp. 127-159). Buenos Aires: Editorial La Colmena.

Salvatore, R.D. (2010). Criminología y cultura estatal. En Subalternos, derechosy justicia penal. Ensayos de historia social y cultural argentina 1829-1940 (pp. 283-325). México DF: Gedisa. 
Salvatore, R.D. (2013). Usos científicos en La Mala Vida de Eusebio Gómez. En R.D. Salvatore y O. Barreneche (Eds.), El delito y el orden en perspectiva histórica (pp. 99-120). Rosario: Prohistoria.

Scarzanella, E. (2015). Ni gringos ni indios. Inmigración, criminalidad y racismo en la Argentina, 1890-1940. Bernal: Universidad de Quilmes.

Scribano, A. (2008). El proceso de investigación social cualitativo. Buenos Aires: Prometeo.

Sozzo, M. (2006). Tradutore Traditore. Traducción, Importación Cultural e Historia del Presente de la Criminología en América Latina. En M. Sozzo (Coord.), Reconstruyendo las Criminologías Criticas (pp. 353-431). Buenos Aires: Ad-Hoc.

Sozzo, M. (2011). 'Los exóticos del crimen'. Inmigración, delito y criminología positivista en la Argentina (1887-1914). Revista Delito y Sociedad, 19(32), 19-51.

\section{Notas}

1 Quiero aclarar que mantuve la denominación de ellas tal como aparecen enunciadas en los artículos consultados (Gori, 1899 c, 1899d). 